\title{
Genotipos de Giardia duodenalis en muestras de niños de las guarderías del Instituto Colombiano de Bienestar Familiar y de perros en Ibagué, Colombia
}

\author{
Victoria Rodríguez ${ }^{1,2}$, Oneida Espinosa', Julio César Carranza'1, Sofía Duque ${ }^{3}$, Adriana Arévalo³ $^{3}$ \\ Jairo Alfonso Clavijo ${ }^{4}$, Daniel Alfonso Urrea ${ }^{1}$, Gustavo Adolfo Vallejo ${ }^{1}$ \\ 1 Laboratorio de Investigaciones en Parasitología Tropical, Facultad de Ciencias, Departamento de Biología, \\ Universidad del Tolima, Ibagué, Colombia \\ 2 Facultad de Medicina Veterinaria y Zootecnia, Universidad del Tolima, Ibagué, Colombia \\ ${ }^{3}$ Grupo de Parasitología, Subdirección de Investigación Científica y Tecnológica, Dirección de Investigación en \\ Salud Pública, Instituto Nacional de Salud, Bogotá, D.C., Colombia \\ 4 Departamento de Matemáticas y Estadística, Facultad de Ciencias, Universidad del Tolima, Ibagué, Colombia
}

Introducción. Se han descrito ocho genotipos de Giardia duodenalis, del A al H. Los genotipos A y B se han aislado de humanos y de una gran variedad de mamíferos; sin embargo, los genotipos del $\mathrm{C}$ al $\mathrm{H}$ han mostrado mayor especificidad de huésped.

Objetivo. Identificar los genotipos de G. duodenalis a partir de quistes obtenidos en heces de niños de las guarderías del Instituto Colombiano de Bienestar Familiar (ICBF) y de perros en Ibagué, mediante PCR-RFLP de los genes de la beta giardina y la glutamato deshidrogenasa.

Materiales y métodos. Los quistes de las muestras positivas para G. duodenalis fueron sometidos a concentración; se extrajo su ADN y se efectuó el análisis de PCR-RFLP de los genes de la beta giardina y de la glutamato deshidrogenasa. Como control positivo se utilizó la cepa MHOM/CO/04/G40 procedente del Grupo de Parasitología del Instituto Nacional de Salud.

Resultados. De las muestras tomadas de niños, 11/23 (48 \%) correspondieron al genotipo A y, 12/23 (52 \%), al genotipo B. Cuatro muestras de perros presentaron los genotipos C y D, específicos de este huésped.

Conclusiones. En los niños solamente se encontraron los genotipos asociados a infecciones humanas (AII, BIII y BIV) y en los perros, los genotipos específicos para este huésped (C y D). Debido al reducido tamaño de las muestras analizadas provenientes de perros, y dado que estos no estuvieron en contacto con los niños de las guarderías del ICBF, no fue posible determinar una interacción entre el ciclo de transmisión de los humanos y el de los animales.

Palabras clave: Giardia duodenalis, glutamato deshidrogenasa, niño, perros.

doi: http://dx.doi.org/10.7705/biomedica.v34i2.1713

\section{Giardia duodenalis genotypes found in the Instituto Colombiano de Bienestar Familiar day care centers and dogs in Ibagué, Colombia}

Introduction: Eight Giardia duodenalis genotypes $(\mathrm{A}-\mathrm{H})$ have been described to date. Genotypes $A$ and $B$ have been isolated from humans and a wide range of mammals; however, genotypes $\mathrm{C}-\mathrm{H}$ have shown greater host specificity.

Objective: Identifying G. duodenalis genotypes from cysts in faeces obtained from children attending the Instituto Colombiano de Bienestar Familiar (ICBF) day care centres and from dogs in lbagué by PCR-RFLP targeting both the $\beta$-giardin and glutamate dehydrogenase genes.

Materials and methods: Cysts from $G$. duodenalis positive samples were concentrated, DNA was extracted and the $\beta$-giardin and glutamate dehydrogenase genes were analysed by PCR-RFLP. The $\mathrm{MHOM} / \mathrm{CO} / 04 / \mathrm{G} 40$ strain was used as positive control (this was obtained from the Grupo de Parasitología at the Instituto Nacional de Salud).

\section{Contribución de los autores:}

Victoria Rodríguez, Oneida Espinosa y Julio César Carranza: recolección de muestras de campo, trabajo de laboratorio, análisis de datos y revisión de resultados

Sofía Duque y Adriana Arévalo: análisis de datos y revisión de resultados

Jairo Alfonso Clavijo: análisis estadístico y determinación del tamaño de la muestra a analizar

Daniel Alfonso Urrea: revisión de resultados

Gustavo Adolfo Vallejo: orientación del trabajo de campo y de laboratorio, análisis de datos y revisión de resultados

Todos los autores participaron en la elaboración del manuscrito. 
Results: Of the total human samples, 11/23 (48\%) were genotyped as A and 12/23 (52\%) as B; PCRRFLP revealed that four canine samples were genotypes $C$ and $D$, these being host-specific.

Conclusions: Only genotypes associated with human infection (AII, BIII and BIV) were found in the children and host-specific genotypes were observed in canines ( $C$ and $D)$. No interaction could be established between animal and human transmission cycles due to the small canine sample size and as the former did not come into contact with children attending ICBF day-care centres.

Key words: Giardia duodenalis, glutamate dehydrogenase, child, dogs.

doi: http://dx.doi.org/10.7705/biomedica.v34i2.1713

La giardiosis es una parasitosis de distribución cosmopolita causada por Giardia duodenalis (sinónimo, Giardia intestinalis y Giardia lamblia). Este protozoo flagelado coloniza el intestino de seres humanos y animales, produciendo una enfermedad que puede ser asintomática, aguda o crónica, con cuadros diarreicos de intensidad variable que puede llegar a ocasionar síndrome de mala absorción (1). Cerca de 200 millones de personas en Asia, África y América Latina presentan síntomas de giardiosis, con una incidencia de infección de 500.000 casos por año (2).

Giardia duodenalis ha sido descrita en seres humanos, así como en otros mamíferos domésticos y silvestres (3). En algunos estudios recientes se ha sugerido que esta especie debería considerarse como un complejo de especies cuyos miembros, aunque morfológicamente idénticos, presentan variaciones genéticas que han permitido dividirla en, al menos, ocho genotipos (del A al H) (4).

Se ha demostrado que en la mayoría de los casos solamente los genotipos A y B están asociados con la infección en seres humanos (5), aunque se han reportado casos de personas infectadas con los genotipos específicos del perro, el ganado y el gato (6-9). Los genotipos del $\mathrm{C}$ al $\mathrm{H}$ parecen ser específicos de huésped, pues el $C$ y el $D$ se han reportado principalmente en cánidos (domésticos y silvestres), el E está fuertemente relacionado con animales ungulados, el $\mathrm{F}$ y el $\mathrm{G}$ han sido detectados en gatos y ratas, respectivamente (3), y el genotipo $\mathrm{H}$ fue descrito recientemente en focas grises y en una gaviota austral (10).

La caracterización directa de los quistes de $G$. duodenalis mediante la técnica de PCR se ha utilizado para esclarecer el papel zoonótico de

\section{Correspondencia:}

Gustavo Adolfo Vallejo, Laboratorio de Investigaciones en Parasitología Tropical, Facultad de Ciencias, Universidad del Tolima, Ibagué, Colombia

Telefax: (578) 2770192

gvallejo@ut.edu.co

Recibido: 27/06/13; aceptado: 06/03/14 los diferentes genotipos (11). El genotipo A puede dividirse en, por lo menos, tres subgrupos: el primero (Al), detectado en seres humanos y en animales, presenta un mayor potencial zoonótico; el segundo (All), observado principalmente en seres humanos, y el tercero (AIII), aparentemente específico de especie, ha sido aislado de ungulados silvestres (12).

El genotipo B comprende dos subgrupos reconocidos, el BIII y el BIV, que se han asociado principalmente a los seres humanos, aunque también existen algunos reportes en animales $(13,14)$. Sin embargo, comparado con el A, este genotipo presenta un gran polimorfismo, que lleva a pensar en la existencia de muchos más subtipos (15).

Se plantea la posibilidad de que los genotipos A y $B$ correspondan a dos especies diferentes, pues los estudios genómicos han permitido observar que solamente existe $77 \%$ de identidad de nucleótidos y $78 \%$ de identidad de aminoácidos en regiones codificadoras, lo que corrobora las diferencias biológicas encontradas en las infecciones experimentales, en el crecimiento en cultivos y en los estudios citogenéticos (16).

Para esclarecer el potencial zoonótico de las infecciones con $G$. duodenalis en animales, es importante determinar si los seres humanos y otros huéspedes son vulnerables ante infecciones con formas genéticamente idénticas del parásito $(3,17)$.

Dado que en Colombia se sabe poco sobre este aspecto, y que específicamente en Ibagué no se han efectuado estudios sobre la diversidad molecular de G. duodenalis, en este trabajo se determinaron los genotipos a partir de los quistes recuperados de las heces de los niños del Instituto Colombiano de Bienestar Familiar y caninos, empleando la técnica PCR-RFLP de los genes de la beta giardina $(b g)$ y de la glutamato deshidrogenasa $(g d h)$.

\section{Materiales y métodos}

\section{Muestras y análisis coproparasitológico}

Se recolectaron muestras de niños en edad preescolar (1 a 5 años) y de otras personas adultas en 
once hogares infantiles empresariales y comunales adscritos al Instituto Colombiano de Bienestar Familiar en Ibagué entre febrero y junio del 2009.

Se determinó el tamaño de la muestra con un nivel de confianza de $95 \%(Z=1,96)$, un valor $p$ de 0,5 y un margen de error de $10 \%(0,05)$. A partir de una población de 2.157 niños en edad preescolar en los hogares del Instituto Colombiano de Bienestar Familiar, se hizo la corrección por finitud del tamaño de la muestra estableciendo un mínimo de 327 niños. Para la selección de la muestra, se utilizó un muestreo probabilístico aleatorio simple. La prevalencia de niños en edad preescolar con giardiosis, se determinó calculando intervalos de confianza (IC) mediante la distribución por aproximación normal.

Al inicio del proyecto se consultó si los niños que asistían a los hogares del Instituto Colombiano de Bienestar Familiar en Ibagué tenían mascotas en sus viviendas, y se encontró que solamente una proporción muy baja las tenía. Por esta razón, se decidió tomar las muestras de los perros en centros veterinarios y refugios animales. Consecuentemente, no se determinó un tamaño de muestra que fuera representativa de la población de perros de Ibagué. El diagnóstico coproparasitológico de niños y de perros se hizo mediante tinción con lugol y observación directa con el microscopio.

\section{Concentración de quistes y obtención de ácidos nucleicos}

Las muestras positivas para quistes se procesaron mediante flotación de Faust (18). Los quistes se suspendieron en solución tampón de lisis $(\mathrm{NaCl}$ $5 \mathrm{M}$, EDTA 0,5M, SDS $10 \%$ y para su ruptura se sometieron a cinco ciclos de congelamiento y descongelamiento en nitrógeno líquido (15 minutos), y en baño serológico a $65{ }^{\circ} \mathrm{C}$ (15 minutos), respectivamente. Luego se incubaron con proteinasa $\mathrm{K}(200 \mu \mathrm{g} / \mathrm{ml})$ a $37^{\circ} \mathrm{C}$ durante toda la noche. Los ácidos nucleicos se extrajeron con el estuche QIAamp DNA Mini Kit ${ }^{\circledR}$ de QIAGEN, siguiendo las instrucciones del fabricante. Las muestras que presentaron problemas en la amplificación debido a la baja cantidad de ADN, se concentraron con acetato de sodio $3 \mathrm{M}$ y etanol absoluto, se suspendieron de nuevo en $20 \mu$ de TE (Tris-EDTA, pH 8,0) y se almacenaron a $4{ }^{\circ} \mathrm{C}$ hasta su posterior análisis. Como cepa de referencia para la extracción del ADN y el posterior análisis por medio de PCR-RFLP, se utilizó la cepa MHOM/ CO/04/G40 mantenida en cultivo, procedente del Instituto Nacional de Salud.

\section{PCR-RFLP del gen de la beta giardina}

Se amplificó un fragmento de 753 pb del gen de la beta giardina usando los iniciadores $\mathrm{G} 7$ (5'-AA GCCCGACGACCTCACCCGCAGTGC- 3') y G759 (5'-GAGGCCGCCCTGGATCTTCGAGACGAC-3') y se obtuvo un fragmento de $384 \mathrm{pb}$ con una segunda reacción de PCR semianidada utilizando los iniciadores G376 (5'-CATAACGACGCCATCG CGGCTCTCAGGAA-3') y G759 (5'-GAGGCCG CCCTGGATCTTCGAGACGAC-3') (5). La mezcla de reacción utilizada fue la siguiente: solución tampón 1X de la polimerasa ADN Taq, 1,5 mM $\mathrm{MgCl}_{2}, 200 \mu \mathrm{M}$ de la mezcla de dNTP, $20 \mathrm{pmol}$ de cada iniciador, $1 U$ de polimerasa ADN Taq y $2 \mu \mathrm{l}$ de ADN, para un volumen final de $20 \mu \mathrm{l}$. La reacción se efectuó en un termociclador Minicycler con una temperatura de desnaturalización de $94^{\circ} \mathrm{C}$ durante cinco minutos, seguido de 35 ciclos a $94{ }^{\circ} \mathrm{C}$ durante 30 segundos, a $65^{\circ} \mathrm{C}$ durante 30 segundos, a $72{ }^{\circ} \mathrm{C}$ durante un minuto y un ciclo de extensión final a $72{ }^{\circ} \mathrm{C}$ durante siete minutos. Además, se incluyeron un control de reacción (mezcla de reacción sin ADN) y un control positivo para G. duodenalis de ADN extraído de trofozoítos cultivados en medio TYIS-33 (cepa MHOM/CO/04/ G40) cedida para estudios de investigación por el Instituto Nacional de Salud.

Las alícuotas de $10 \mu \mathrm{l}$ de los productos de PCR se digirieron con Hae III (para el fragmento de $753 \mathrm{pb}$ ) y con tha I (para el fragmento de 384 $\mathrm{pb})$, utilizando dos unidades de la enzima en un volumen final de $20 \mu$ durante cuatro horas a $37^{\circ} \mathrm{C}$. Los productos de digestión esperados se muestran en el cuadro 1.

\section{PCR-RFLP del gen de la glutamato deshidrogenasa}

Un fragmento de $458 \mathrm{pb}$ del gen de la glutamato deshidrogenasa ( $g d h)$ se amplificó utilizando los iniciadores GDHeF: 5'-TCA ACGTYA AYC GYG GYT TCC GT-3' y GDHiR: 5'-GTT RTC CTT GCA CAT CTC C-3' y un segundo fragmento de $432 \mathrm{pb}$ se obtuvo en una reacción de PCR semianidada, utilizando los iniciadores GDHiF: 5'-CAG TAC AAC TCY GCT CTC GG-3' y GDHiR: 5'-GTT RTC CTT GCA CAT CTC C-3' (20). Las condiciones de amplificación fueron las siguientes: una temperatura de desnaturalización de $94{ }^{\circ} \mathrm{C}$ durante cinco minutos, un ciclo de dos minutos a $94^{\circ} \mathrm{C}$, de un minuto a $56{ }^{\circ} \mathrm{C}$, de dos minutos a $72{ }^{\circ} \mathrm{C}$, seguido de 35 ciclos de 30 segundos a $94{ }^{\circ} \mathrm{C}$, uno de 20 segundos a $56^{\circ} \mathrm{C}$, de 45 segundos a $72{ }^{\circ} \mathrm{C}$ y una extensión final a $72{ }^{\circ} \mathrm{C}$ durante siete minutos. La 
Cuadro 1. Tamaño de los fragmentos esperados $(\mathrm{pb})$ y perfil de las bandas para diagnóstico $(\mathrm{pb})$ de los genotipos de Giardia duodenalis sometidos a PCR-RFLP a partir de un fragmento de $753 \mathrm{pb}$ del gen de la beta giardina digerido con Hae III y un fragmento de $384 \mathrm{pb}$ del mismo gen digerido con Hha I $(5,19)$

\begin{tabular}{lllll}
\hline Genotipo & $\begin{array}{l}\text { Tamaño del fragmento } \\
\text { del gen amplificado }\end{array}$ & $\begin{array}{l}\text { Enzima } \\
\text { (número de } \\
\text { sitios de } \\
\text { restricción) }\end{array}$ & $\begin{array}{l}\text { Tamaño de los fragmentos } \\
\text { esperados (pb) }\end{array}$ & $\begin{array}{l}\text { Perfil de las bandas } \\
\text { para el diagnóstico } \\
\text { de los genotipos (pb) }\end{array}$ \\
\hline A & Beta giardina 753 pb & Hae III (4) & $202,201,150,126,74$ & $200,200,150,130$ \\
B & Beta giardina 753 pb & Hae III (5) & $202,176,150,117,84,24$ & $200,180,150,120,80$ \\
C & Beta giardina 753 pb & Hae III (6) & $286,150,126,102,70,15,4$ & $290,150,130,100,70$ \\
D & Beta giardina 753 pb & Hae III (3) & $346,286,117,4$ & $350,290,120$ \\
A1 & Beta giardina 384 pb & Hha I (3) & $193,104,70,17$ & $190,100,70$ \\
All/AIII & Beta giardina 384 pb & Hha I (3) & $210,70,70,34$ & 210,70 \\
\hline
\end{tabular}

Cuadro 2. Tamaño de los fragmentos esperados (pb) y perfil de las bandas para diagnóstico (pb) de los genotipos de Giardia duodenalis sometidos a PCR-RFLP de un fragmento de $432 \mathrm{pb}$ del gen de la glutamato deshidrogenasa (gdh) digerido con Nla IV y Rsa I (20)

\begin{tabular}{lllll}
\hline Genotipo & $\begin{array}{l}\text { Tamaño del } \\
\text { fragmento del } \\
\text { gen amplificado }\end{array}$ & $\begin{array}{l}\text { Enzima (número } \\
\text { de sitios de } \\
\text { restricción) }\end{array}$ & $\begin{array}{l}\text { Tamaño de los fragmentos } \\
\text { esperados (pb) }\end{array}$ & $\begin{array}{l}\text { Perfil de las bandas } \\
\text { para el diagnóstico } \\
\text { de los genotipos (pb) }\end{array}$ \\
\hline A1 & gdh $432 \mathrm{pb}$ & Nla IV (5) & $149,123,87,39,18,16$ & $150,120,90$ \\
All & gdh $432 \mathrm{pb}$ & Nla IV (6) & $123,87,77,72,39,16,18$ & $120,90,80,70$ \\
BIII & gdh 432 pb & Nla IV (2) & $291,123,18$ & 290,120 \\
BIV & gdh 432 pb & Nla IV (2) & $291,123,18$ & 290,120 \\
C & gdh 432 pb & Nla IV (4) & $187,123,72,31,18$ & $190,120,70$ \\
D & gdh 432 pb & Nla IV (3) & $249,126,39,18$ & 250,120 \\
BIII & gdh 432 pb & Rsa I (2) & 297,133 & 300,130 \\
BIV & gdh 432 pb & Rsa (1) & 432 & 430 \\
\hline
\end{tabular}

mezcla de la reacción de la PCR, los controles de la reacción, el control positivo y el termociclador, fueron los mismos empleados para la amplificación del gen de la beta giardina.

Las alícuotas de $10 \mu \mathrm{l}$ del fragmento de $432 \mathrm{pb}$ se digirieron con Nla IV (Bsp LI) y Rsa I, empleando dos unidades de la enzima en un volumen final de $20 \mu$ durante tres horas a $37^{\circ} \mathrm{C}$. Los productos de digestión esperados se muestran en el cuadro 2.

\section{Visualización de los productos de PCR-RFLP}

Los productos amplificados se visualizaron en geles de agarosa al $1 \%$ coloreados con bromuro de etidio. Los productos de digestión se sometieron a electroforesis en geles de poliacrilamida al $6 \%$ y se colorearon con nitrato de plata o bromuro de etidio.

\section{Aspectos éticos}

En cada uno de los once hogares comunitarios del Instituto Colombiano de Bienestar Familiar se efectuaron reuniones informativas sobre parasitismo intestinal, a las que asistieron los padres o responsables de los niños y las directoras de los hogares comunitarios, en las cuales se les invitó a participar voluntariamente en el estudio. Se les informó sobre los objetivos y beneficios del estudio y, una vez obtenidos los consentimientos informados, se suministraron las cajas estériles para la recolección de las muestras fecales. Los resultados de los exámenes coprológicos se entregaron a las directoras de los hogares comunitarios con el fin de que enviaran a los niños a los centros de salud para someterlos a tratamiento en caso de ser positivos para G. duodenalis u otros parásitos intestinales.

El proyecto fue aprobado por el Comité Central de Investigaciones y Desarrollo Científico de la Universidad del Tolima después de verificar que los protocolos propuestos se ajustaran a las normas éticas para trabajos con la comunidad y con menores de edad, de conformidad con la Resolución 008430 del 4 de octubre de 1993 del Ministerio de Salud de Colombia.

\section{Resultados}

\section{Prevalencia de Giardia duodenalis}

Se analizaron 331 muestras fecales de niños, de las cuales, 174 correspondían a niños (52,57\%) y 157 , a niñas $(47,43 \%)$. Treinta y siete muestras fueron positivas para $G$. duodenalis, 24 de niños $\left(13,79 \% ; I_{95 \%} 8,63-18,95 \%\right)$ y 13 de niñas $(8,28 \%$; 
$I_{95 \%}$ 3,97-12,59\%); se estableció que para el 2009 la prevalencia de giardiosis en los niños del Instituto Colombiano de Bienestar Familiar fue de $11,17 \%\left(\mathrm{IC}_{95 \%} 7,78-14,58 \%\right)$ y que no hubo diferencias significativas entre sexos. Igualmente, se analizaron seis muestras de niños mayores de cinco años y de adultos, de las cuales, dos fueron positivas para el parásito.

Con relación a las muestras fecales de perros, se recolectaron 119 muestras, 26 de cachorros $(21,85 \%)$ y 93 de adultos $(78,15 \%)$; de estas, el $14,28 \%(17 / 119)$ fue positivo para $G$. duodenalis.

\section{Genotipificación mediante PCR-RFLP del gen de la beta giardina}

Se logró la amplificación de los fragmentos de 753 $\mathrm{pb}$ y de $384 \mathrm{pb}$ en la primera y segunda rondas de PCR en 22 de las 37 muestras positivas de niños y de un adulto.

Los perfiles de restricción de Hae III a partir del fragmento de $753 \mathrm{pb}$ de la beta giardina, permitieron discriminar los genotipos $A, B, C$ y $D$ (figura 1). Por otro lado, los perfiles de restricción de Hha I a partir del fragmento de $384 \mathrm{pb}$, permitieron discriminar los genotipos AI, All y Alll (figura 2). La cepa de referencia MHOM/CO/04/ G40 de G. duodenalis, cedida por el Instituto Nacional de Salud, correspondió al genotipo Al de acuerdo con el perfil de restricción descrito por
Cacciò, et al. (5). El tamaño de los fragmentos de restricción esperados se muestra en el cuadro 1. Se designó un perfil de diagnóstico para cada enzima redondeando el tamaño de los fragmentos para simplificar el análisis de los geles. Los fragmentos de menos de 50 pb no se incluyeron, dado que no migran fuera del gel y porque los genotipos se pueden distinguir sin necesidad de analizar las bandas de menos de 50 pb, según los reportes de Cacciò, et al. (5), Lebbad, et al. (19) y Read, et al. (20).

Entre los aislamientos humanos, 11/23 (47,82 \%) correspondieron al genotipo A (subgrupo All /AIII) y $12 / 23(52,17 \%)$ presentaron el perfil del genotipo $B$ (figuras 1 y 2 ).

Del total de las muestras de origen canino obtenidas de la unidad de refugio animal o coso municipal y del Centro Veterinario de la Asociación Ibaguereña Protectora de Animales, se pudo hacer la genotipificación de $3 / 17(17,84 \%)$ de las muestras positivas, y se encontraron los genotipos específicos de huésped $C(1 / 3)$ y $D(2 / 3)$ (figura 1$)$.

\section{Genotipificación mediante PCR-RFLP del gen de la glutamato deshidrogenasa}

El gen gdh se amplificó en 20/37 (54,05 \%) de las muestras fecales positivas para $G$. duodenalis tomadas de niños en edad preescolar, de un niño de edad desconocida y de un adulto.

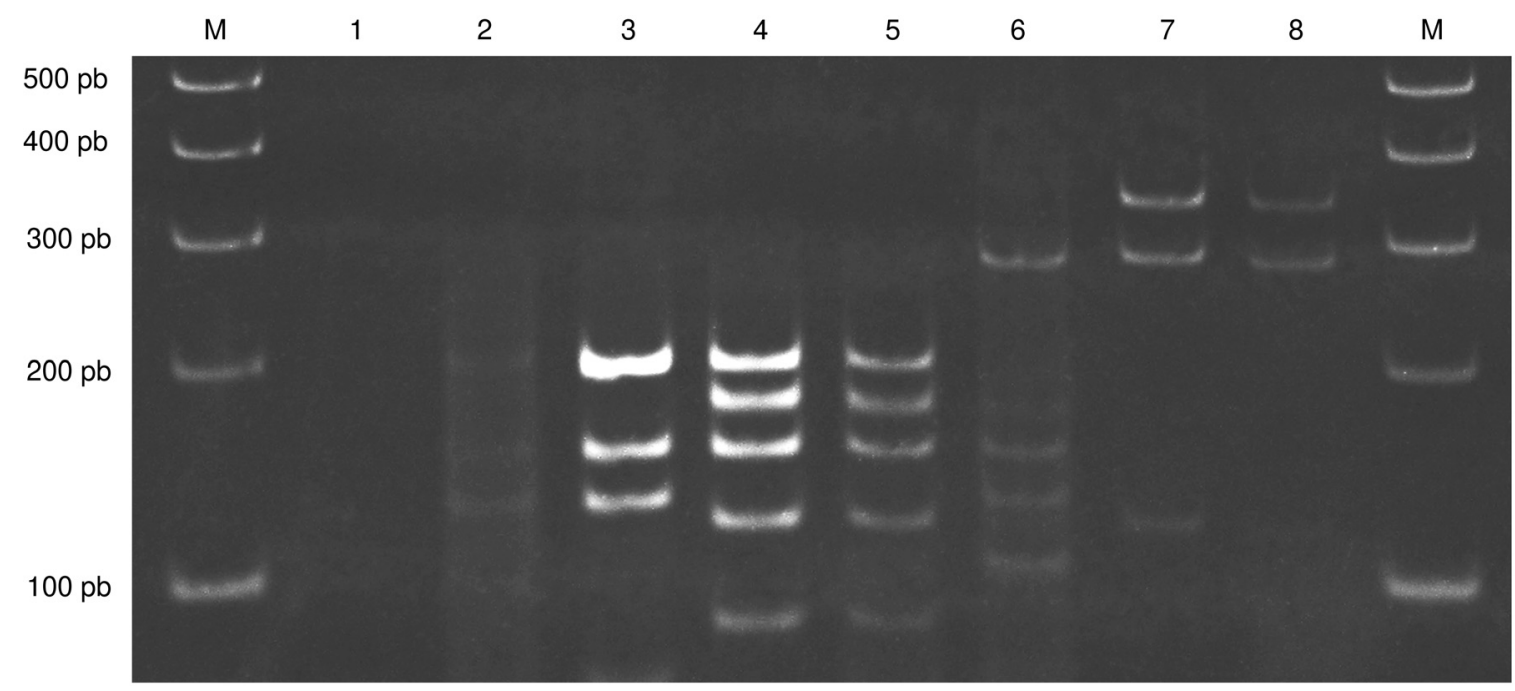

Figura 1. Gel de poliacrilamida al $6 \%$ teñido con bromuro de etidio que muestra los fragmentos de restricción del producto de 753 $\mathrm{pb}$ del gen de la beta giardina con la enzima de restricción Hae III

M: marcador de tamaño molecular de 100 pb; 1: control de reacción; 2: cepa de referencia MHOM/CO/04/G40 (genotipo A: 200, 150, 130 pb); 3: H292 (genotipo A: 200, 150, 130 pb); 4: H018 (genotipo B: 200, 180, 150, 120, 80 pb); 5: H355 (genotipo B: 200 , 180, 150, 120, 80 pb); 6: perro 113 (genotipo C: 290, 150, 130, 100 pb); 7: perro 17 (genotipo D: 350, 290, 120 pb); 8: perro 16 (genotipo D: 350, 290, $120 \mathrm{pb)}$ 


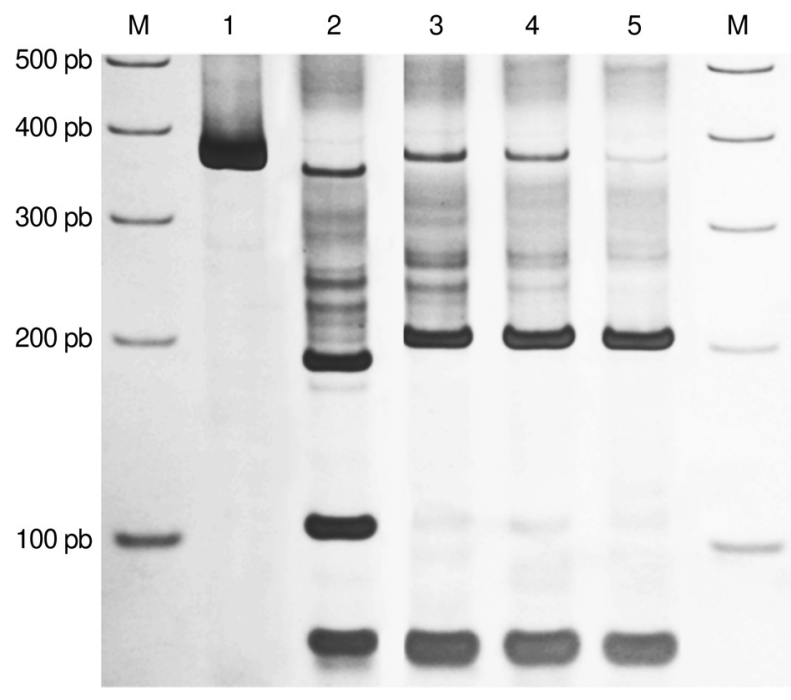

Figura 2. Gel de poliacrilamida al $6 \%$ teñido con nitrato de plata que muestra los fragmentos de restricción del producto de $384 \mathrm{pb}$ del gen de la beta giardina con la enzima de restricción Hha I

M: marcador de tamaño molecular de $100 \mathrm{pb}$; 1: control sin digerir; 2: cepa de referencia MHOM/CO/04/G40 (genotipo Al: 190, 100, $70 \mathrm{pb}$ ); 3-5: aislamientos de seres humanos (genotipo All / Alll: 210, 70, $70 \mathrm{pb}$ )

Los perfiles de restricción de la Nla IV a partir del fragmento de $432 \mathrm{pb}$ de la glutamato deshidrogenasa, permitieron discriminar los genotipos $\mathrm{Al}$, All, B, C y D (figura 3). Utilizando esta estrategia, la cepa de referencia MHOM/CO/04/G40 de G. duodenalis, cedida por el Instituto Nacional de Salud, correspondió al genotipo Al, de acuerdo con el perfil de restricción descrito por Read, et al. (20). Por otro lado, los perfiles de restricción de la Rsa I a partir del fragmento de $432 \mathrm{pb}$, permitieron discriminar los genotipos BIII y BIV (figura 4). EI tamaño de los fragmentos de restricción esperados se muestra en el cuadro 2. Se designó un perfil de diagnóstico para cada enzima redondeando el tamaño de los fragmentos para simplificar el análisis de los geles. Los fragmentos de menos de $50 \mathrm{pb}$ no se incluyeron en el análisis dado que no migran fuerra del gel y porque, de conformidad con los reportes de Cacciò, et al. (5) y de Read, et al., los genotipos de $G$. duodenalis se pueden distinguir sin necesidad de analizar las bandas de menos de $50 \mathrm{pb}$ (20).

Entre los aislamientos de humanos, 10/22 (45,45\%) correspondieron al genotipo A (subgrupo All), y 12/22 (54,55 \%), al genotipo B (cuatro al BIII, dos al BIV, cinco a la mezcla de BIII y BIV y uno que no se pudo determinar) (figuras 3 y 4 ). Los genotipos A y $B$ se distribuyeron equitativamente entre niños y niñas; el único adulto, una mujer, presentó el genotipo B (cuadro 3).

Se hizo la genotipificación de 4/17 muestras fecales de perros de los centros veterinarios ya mencionados (figura 3), en las cuales se encontraron los genotipos específicos del huésped $C(2 / 4)$ y $D(2 / 4)$.

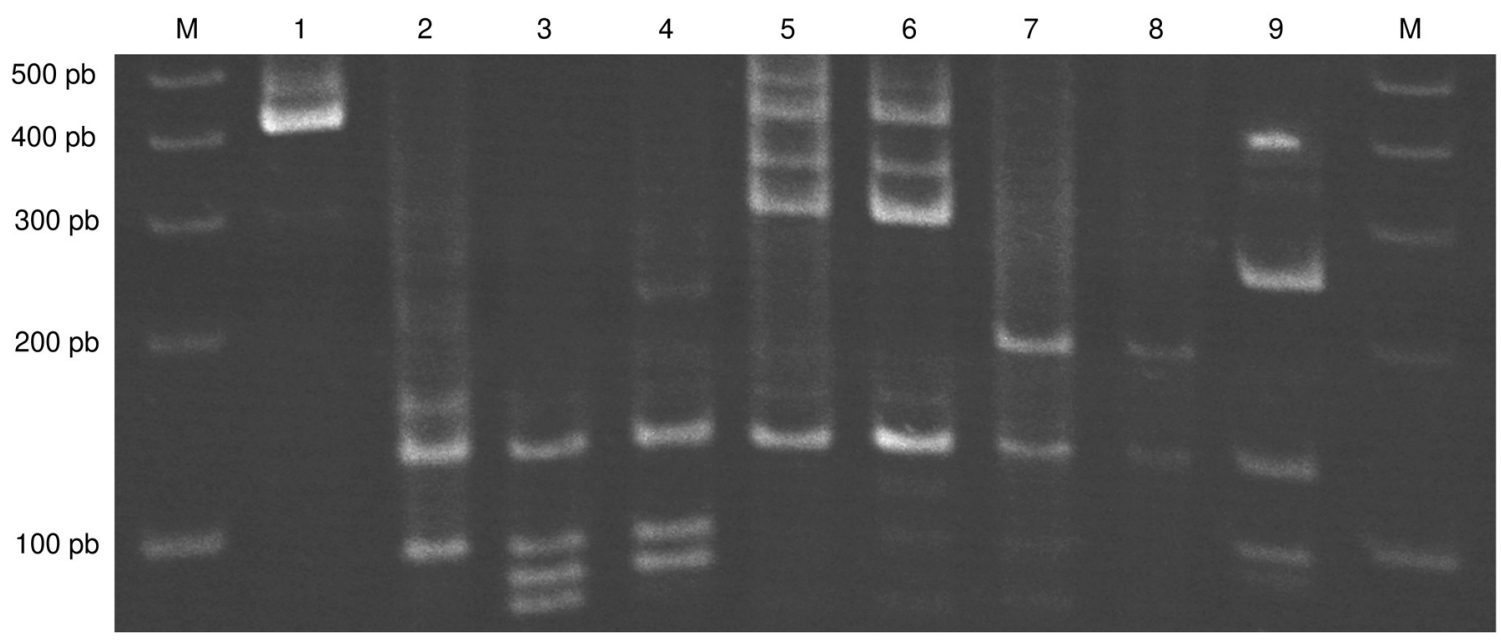

Figura 3. Gel de poliacrilamida al $6 \%$ teñido con bromuro de etidio que muestra los fragmentos de restricción del producto de 432 $\mathrm{pb}$ del gen de la glutamato deshidrogenasa con la enzima de restricción Nla IV

M: marcador de tamaño molecular de 100 pb; 1: control sin digerir; 2: cepa de referencia MHOM/CO/04/G40 (genotipo Al: 150, 120, 90 pb); 3: H292 (genotipo All:120, 90, 80, 70 pb); 4: H323 (genotipo All: 120, 90, 80, 70); 5: H018 (genotipo B: 290,120 pb; las bandas de más de 290 pb constituyen productos de digestión parcial); 6: H355 (genotipo B: 290, 120 pb; las bandas de más de 290 pb constituyen productos de digestión parcial); 7: perro 113 (genotipo C: 190, 120, 70 pb); 8: perro 20 (genotipo C: 190, 120,70 pb); 9: perro 17 (genotipo D: 250, 120 pb) 


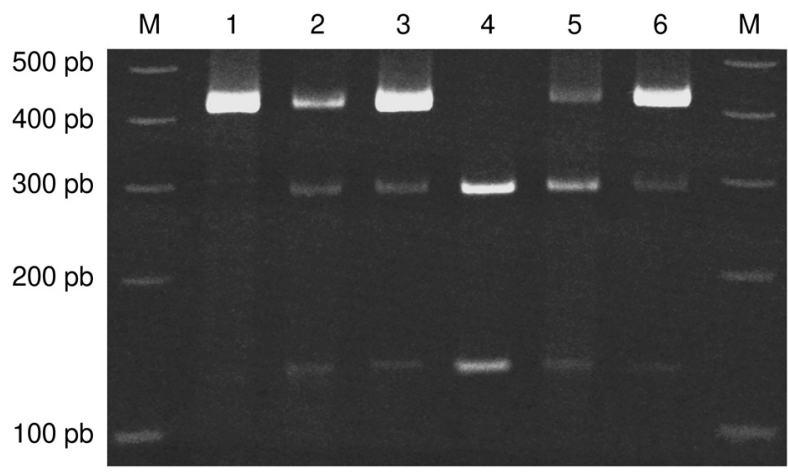

Figura 4. Gel de poliacrilamida al $6 \%$ teñido con bromuro de etidio que muestra los fragmentos de restricción del producto de $432 \mathrm{pb}$ del gen de la glutamato deshidrogenasa con la enzima de restricción $R s a$ I

M: marcador de tamaño molecular de $100 \mathrm{pb}$; 1: control sin digerir, 432 pb; 2: H227 (mezcla de BIII y BIV); 3: H275 (mezcla de BIII y BIV); 4: H159 (genotipo BIII: 300, 130 pb); 5: H004 (mezcla de BIII y BIV); 6: H355 (mezcla de BIII y BIV)

\section{Discusión}

Los estudios de prevalencia de giardiosis en Colombia demuestran que las condiciones higiénicas están estrechamente relacionadas con la persistencia del protozoario. En el 2002 se reportó en Armenia una prevalencia de $60,4 \%$ en niños afectados por el terremoto de ese año que habitaban albergues temporales (21). Años más tarde, en esa misma ciudad se reportó que la prevalencia había descendido a $13 \%$ en niños que tenían mejores condiciones de estudio y vivienda (22). En el último estudio sobre parasitismo intestinal en niños llevado a cabo en Ibagué (1988 a 1989), se reportó una prevalencia de $41,4 \%$ de $G$. duodenalis (23). No se encontraron registros sobre el tema de los siguientes 20 años, por lo cual el presente trabajo brinda la información más reciente que se tiene sobre giardiosis en preescolares entre 1 y 5 años de edad.

La prevalencia de giardiosis encontrada en los 331 niños en edad preescolar incluidos en la muestra de este trabajo fue de $11,17 \%\left(\mathrm{IC}_{95 \%}, 7,78-14,58\right)$, considerablemente inferior a la registrada hace 20 años (23). Esto podría indicar que las condiciones higiénico-sanitarias han mejorado, así como el control y el tratamiento de esta parasitosis. De acuerdo con Thompson (24) y Santos, et al., (25) la alta prevalencia en hogares infantiles sugiere un patrón similar al observado en infecciones entéricas bacterianas, las cuales aparecen en un niño, se difunden rápidamente y permanecen en el ambiente como fuentes de infección.

Cuadro 3. Genotipos de Giardia duodenalis determinados mediante PCR-RFLP de los genes de la beta giardina y la glutamato deshidrogenasa

\begin{tabular}{|c|c|c|c|c|c|}
\hline Código aislado & Huésped & Sexo & Edad (años) & Genotipo bg & Genotipo gdh \\
\hline $\mathrm{H} 004$ & Humano & M & 1 & $\mathrm{~B}$ & BIII-BIV \\
\hline H018 & Humano & $\mathrm{F}$ & 2 & $\mathrm{~B}$ & BIII \\
\hline H022 & Humano & $\mathrm{F}$ & 2 & All & All \\
\hline H033 & Humano & $\mathrm{F}$ & 2 & $\mathrm{~B}$ & BIII \\
\hline H050 & Humano & $M$ & 2 & B & BIII-BIV \\
\hline H055 & Humano & $M$ & 2 & $B$ & B \\
\hline H068 & Humano & $M$ & 2 & $B$ & BIII \\
\hline $\mathrm{H} 101$ & Humano & $\mathrm{F}$ & 3 & All & All \\
\hline $\mathrm{H} 104$ & Humano & $\mathrm{F}$ & 3 & All & All \\
\hline $\mathrm{H} 159$ & Humano & M & 3 & $B$ & BIII \\
\hline $\mathrm{H} 170$ & Humano & M & 3 & B & BIV \\
\hline $\mathrm{H} 186$ & Humano & M & 3 & All & All \\
\hline H195 & Humano & M & 3 & All & All \\
\hline H227 & Humano & $\mathrm{F}$ & 4 & $B$ & BIII-BIV \\
\hline H246 & Humano & $\mathrm{F}$ & 4 & B & BIV \\
\hline $\mathrm{H} 275$ & Humano & $M$ & 4 & $B$ & BIII-BIV \\
\hline H292 & Humano & $M$ & 4 & All & AII \\
\hline H308 & Humano & M & 4 & All & All \\
\hline H323 & Humano & M & 4 & All & All \\
\hline H326 & Humano & M & 4 & All & All \\
\hline H342 & Humano & $M$ & ND & All & All \\
\hline H355 & Humano & $\mathrm{F}$ & Adulto & $\mathrm{B}$ & BIII-BIV \\
\hline Perro 16 & Perro & ND & Cachorro & $\mathrm{D}$ & D \\
\hline Perro 17 & Perro & ND & Cachorro & $\mathrm{D}$ & $D$ \\
\hline Perro 20 & Perro & ND & Cachorro & ND & $\mathrm{C}$ \\
\hline Perro 113 & Perro & ND & Adulto & C & C \\
\hline
\end{tabular}

ND: no determinado 
Al comparar los datos con los de otras naciones de Suramérica, la prevalencia de infección registrada en el presente trabajo resultó inferior a la reportada en países como Brasil en 1991 (26) y Venezuela en el 2007 (27), con valores entre 27,7 y $26,73 \%$, respectivamente. En la mayoría de los hogares del Instituto Colombiano de Bienestar Familiar analizados en Ibagué (10/11), siempre se encontró, al menos, a un niño con giardiosis, sin importar su estrato o ubicación, lo cual indica que las fuentes de infección del parásito se encuentran dispersas en la ciudad.

La prevalencia de giardiosis en perros fue de $14,28 \%$, inferior a lo que se ha reportado en países desarrollados como Italia (20,5\%) (28) y Bélgica $(43,9 \%)$ en perros mantenidos en condiciones de hacinamiento (29). En América Latina, en algunos estudios de perros domésticos se encontraron prevalencias menores a las reportadas en nuestro trabajo, que fluctuaban entre $0,9 \%$ en Huila, Colombia, (30) y 9,3\% en Perú (31).

La caracterización del parásito mediante PCR fue exitosa en $58,97 \%$ (23/39) de las muestras humanas positivas para G. duodenalis; esta disminución en la sensibilidad de la PCR con respecto al método parasitológico pudo deberse a que los blancos de amplificación eran de copia única, al bajo número de quistes o a la presencia de inhibidores de la PCR debida a las características de las muestras.

El análisis de los perfiles de RFLP para ambos genes reveló que las muestras de los niños se agruparon dentro de los genotipos zoonóticos A $(11 / 23=47,83 \%)$ y $B(12 / 23=52,17 \%)$. Este resultado concuerda con lo observado en otros países americanos, como Nicaragua, Brasil, Perú y Argentina $(19,26,31,32)$, en donde se han encontrado también los dos genotipos circulando entre los aislamientos provenientes de las personas analizadas, con valores equiparables a los hallados en Cuba, con nueve aislamientos del genotipo A (45\%) y 11 del genotipo B (55\%) (33).

No obstante, los resultados encontrados en este estudio contrastan con la revisión hecha por Torres, et al. (34) quienes reportaron que México y Colombia eran los únicos países de América en los cuales no se había encontrado el genotipo $B$ en infecciones en seres humanos, debido a que en el único estudio de análisis genético de aislamientos de $G$. duodenalis mediante RAPD publicado en el país se reportaba la presencia de aislamientos del genotipo A (35). Por otra parte, los reportes sobre la genotipificación de aislamientos de $G$. duodenalis de muestras humanas provenientes de Risaralda y Quindío, confirman la presencia de ambos genotipos circulando en el ambiente (A: $84,4 \%$ y B: 4,4 \%) (Lora-Suárez, et al. La genotipificación directa de los aislamientos de Giardia duodenalis por PCR [reacción en cadena de la polimerasa] específico para grupos A y B en Colombia. Memorias, XIV Congreso Colombiano de Parasitología y Medicina Tropical. Biomédica. 2009;29(Supl.1):368-9).

Todas las muestras pertenecientes al genotipo $A$ se agruparon en el subgenotipo All/Alll (subgrupos diferenciables solo por secuenciación) para bg o All para gdh, el cual es más frecuente que el subgrupo Al y está relacionado con aislamientos de muestras de seres humanos (14). Este subgrupo también se halló en todos los aislamientos del genotipo A en Nicaragua y Argentina $(19,32)$, en contraste con lo reportado en Brasil, donde las muestras positivas para el genotipo A pertenecían al subgrupo Al (26).

De acuerdo con los resultados determinados solamente mediante genotipificación con el gen $g d h$, los aislamientos que presentaron el perfil característico del genotipo B se agruparon en los subgrupos BIII (4/12), BIV (2/12) y en la mezcla del BIII y BIV (5/12), lo cual coincide con otros estudios que reportan frecuencias variables en ambos subgrupos. Además, aunque el genotipo B se ha encontrado en algunos animales silvestres y en bovinos, se ha asociado con mayor frecuencia a infecciones en seres humanos (14).

Los genotipos A y B se encontraron con frecuencias de distribución similares según el sexo y la edad de los niños estudiados. Durante nuestro estudio no se tuvo en cuenta la sintomatología del paciente, por lo cual no se pudo hacer una correlación entre el genotipo y las manifestaciones clínicas, como sí lo han hecho otros autores $(36,37)$.

De las muestras positivas para $G$. duodenalis tomadas en los perros, se hizo la genotipificación de 4/17 (23,53\%), y se encontró que estas muestras pertenecían a los genotipos C y D específicos de huésped. Estos resultados difieren de lo observado en la mayoría de los estudios de genotipificación de aislamientos de perros en América, en $60 \%$ de los cuales se reporta la presencia del genotipo A, en $10 \%$, la del genotipo $\mathrm{B}$, y solo en $30 \%$, los genotipos específicos de huésped C y D (34).

El hallazgo de estos genotipos específicos de huésped en nuestro estudio puede deberse al tipo de perros analizados, los cuales se encontraban 
hacinados en refugios y centros de protección de animales. Ya se ha reportado que cuando los perros están agrupados, como sucede en las perreras, es más frecuente la transmisión directa entre los perros $y$, por lo tanto, predominan los genotipos adaptados a tal tipo de huésped. Por el contrario, en los cachorros domésticos hay una menor probabilidad de transmisión de perro a perro y las infecciones con el genotipo A son más frecuentes (38).

Estos resultados difieren de los obtenidos en Quindío y Risaralda (Lora-Suárez, et al. Genotipificación directa de los aislamientos de $G$. duodenalis por PCR [reacción en cadena de la polimerasa] específico para grupos $A$ y $B$ en Colombia. Memorias XIV Congreso Colombiano de Parasitología y Medicina Tropical. Biomédica. 2009;29(Supl.1):368-9). Estos autores encontraron el genotipo A (86,1\%) tanto en las muestras de Giardia tomadas de seres humanos como de animales domésticos (perro y gato), lo cual muestra una diferencia en la distribución de genotipos en Colombia e indica un posible riesgo zoonótico de los animales domésticos en estos departamentos que presentan el genotipo zoonótico Al.

La utilización de la técnica de PCR-RFLP de dos genes diferentes y el hecho de que la identificación de los fragmentos de restricción fue compatible con los fragmentos esperados de los genotipos reportados por Cacciò, et al. (5), Lebbad, et al. (19) y Read, et al. (20), apoyan en su conjunto la validez de los resultados del presente trabajo, en el cual se observó que en los hogares comunitarios del Instituto Colombiano de Bienestar Familiar de lbagué predominó durante el estudio un ciclo de transmisión de persona a persona, pues se encontraron los genotipos All y B que tienen baja frecuencia en animales. Por otro lado, no fue posible confirmar la participación de los perros en la transmisión de $G$. duodenalis a los seres humanos porque los genotipos ( $C$ y $D$ ) específicos de perros se detectaron en cuatro individuos procedentes de perreras y no en perros domésticos.

Por las razones mencionadas, en lbagué y en otras regiones del país, se recomienda hacer estudios de prevalencia y de genotipificación de G. duodenalis en niños y animales domésticos que estén en contacto, para determinar si existe transmisión directa entre estos y así contribuir al conocimiento del papel que juegan los animales como reservorios potenciales de los genotipos zoonóticos de este parásito. Además de la genotipificación a partir de quistes de G. duodenalis, también es importante hacer nuevos aislamientos en cultivos para identificarlos por secuenciación de los genes de la beta giardina $(b g)$, la glutamato deshidrogenasa (gdh) y otros, lo que permitiría organizar una genoteca de los diferentes genotipos de $G$. duodenalis de origen humano o animal que circulan en el país.

\section{Agradecimientos}

Al Instituto Colombiano de Bienestar Familiar, seccional Ibagué, así como a los donantes, las madres comunitarias y los veterinarios que colaboraron en la recolección de las muestras.

\section{Conflicto de intereses}

Los autores declaramos no haber tenido conflictos de intereses durante el desarrollo y la publicación de este trabajo.

\section{Financiación}

Este trabajo fue financiado por el Fondo de Investigaciones, proyecto No. 40207, y por la Facultad de Medicina, Veterinaria y Zootecnia de la Universidad del Tolima.

\section{Referencias}

1. Botero D, Restrepo M. Parasitosis humanas, Cuarta edición. Medellín: Corporación para Investigaciones Biológicas; 2004.

2. World Health Organization. The World Health Report 1996. Fighting disease, fostering development. Geneva: World Health Organization; 1996.

3. Cacciò SM, Ryan U. Molecular epidemiology of giardiasis. Mol Biochem Parasitol. 2008;160:75-80. http://dx.doi.org/10. 1016/j.molbiopara.2008.04.006

4. Lebbad M, Petersson I, Karlsson L, Botero-Klieven $\mathrm{S}$, Anderson JO, Svenungsson B, et al. Multilocus genotyping of human Giardia isolates suggests limited zoonotic transmission and association between assemblage B and flatulence in children. PLOS Negl Trop Dis. 2011;5:110. http://dx.doi.org/10.1371/journal.pntd.0001262

5. Cacciò SM, De Giacomo M, Pozio E. Sequence analysis of the beta-giardin gene and development of a polymerase chain reaction-restriction fragment length polymorphism assay to genotype Giardia duodenalis cysts from human faecal samples. Int J Parasitol. 2002;32:1023-30. http://dx. doi.org/10.1016/S0020-7519(02)00068-1

6. Gelanew T, Lalle M, Hailu A, Pozio E, Cacciò SM. Molecular characterization of human isolates of Giardia duodenalis from Ethiopia. Acta Trop. 2007;102:92-9.

7. Foronda P, Bargues MD, Abreu-Acosta N, Periago MV, Valero MA, Valladares B, et al. Identification of genotypes of Giardia intestinalis of human isolates in Egypt. Parasitol Res. 2008;103:1177-81. http://dx.doi.org/10.1007/s00436008-1113-2

8. Traub R, Inpankaew T, Reid SA, Sutthikornchai C, Sukthana Y, Robertson ID, et al. Transmission cycles 
of Giardia duodenalis in dogs and humans in temple communities in Bangkok - A critical evaluation of its prevalence using three diagnostic tests in the field in the absence of a gold standard. Acta Trop. 2009;111:125-32. http://dx.doi.org/10.1016/j.actatropica.2009.03.006

9. Soliman RH, Fuentes I, Rubio JM. Identification of a novel assemblage B subgenotype and a zoonotic assemblage $C$ in human isolates of Giardia intestinalis in Egypt. Parasitol Inter. 2011;60:507-11. http://dx.doi.org/10.1016/j. parint.2011.09.006

10. Lasek-Nesselquist E, Welch DM, Sogin ML. The identification of a new Giardia duodenalis assemblage in marine vertebrates and a preliminary analysis of $G$. duodenalis population biology in marine systems. Inter $\mathrm{J}$ Parasitol. 2010;40:1063-74. http://dx.doi.org/10.1016/j.jpara. 2010.02.015

11. Lalle M, Pozio E, Capelli G, Bruschi F, Crotti D; Cacciò SM. Genetic heterogeneity at the beta-giardin locus among human and animal isolates of Giardia duodenalis and identification of potentially zoonotic subgenotypes. Inter J Parasitol. 2005;35:207-13. http://dx.doi.org/10.1016/j. ijpara.2004.10.022

12. Cacciò SM, Beck R, Almeida A, Bajer A, Pozio E. Identification of Giardia species and Giardia duodenalis assemblages by sequence analysis of the 5.8S rDNA gene and internal transcribed spacers. Parasitology. 2010;137:91925. http://dx.doi.org/10.1017/S003118200999179X

13. Thompson RC. The zoonotic significance and molecular epidemiology of Giardia and giardiasis. Vet Parasitol. 2004;126:15-35.

14. Sprong H, Cacciò SM, van der Giessen J, ZOOPNET network and partners. Identification of zoonotic genotypes of Giardia duodenalis. PLOS Negl Trop Dis. 2009;3:1-12. http://dx.doi.org/10.1371/journal.pntd.0000558

15. Feng Y, Xiao L. Zoonotic potential and molecular epidemiology of Giardia species and giardiasis. Clin Microbiol Rev. 2011;24:110-40. http://dx.doi.org/10.1128/ CMR.00033-10

16. Jersitröm-Hultqvist J, Ankarklev J, Svärd SG. Is human giardiasis caused by two different Giardia species? Gut Microbes. 2010;1:379-82. http://dx.doi.org/10.4161/gmic.1.6. 13608

17. Thompson RC, Palmer CS, O'Handley R. The public health and clinical significance of Giardia and Cryptosporidium in domestic animals. Vet J. 2008;177:18-25. http://dx.doi. org/10.1016/j.tvjl.2007.09.022

18. Faust EC, D'Antoni JS, Odon V, Miller MJ, Peres C, Sawitz W, et al. A critical study of clinical laboratory technics for the diagnosis of protozoan cysts and helminth eggs in feces. I. Preliminary communication. Am J Trop Med Hyg. 1938;18:169-83.

19. Lebbad M, Ankarklev J, Téllez A, Leiva B, Andersson JO, Svärd S. Dominance of Giardia assemblage B in León, Nicaragua. Acta Trop. 2008;106:44-53. http://dx.doi. org/10.1016/j.actatropica.2008.01.004

20. Read CM, Monis PT, Thompson RC. Discrimination of all genotypes of Giardia duodenalis at the glutamate dehydrogenase locus using PCR-RFLP. Infect Genet Evol. 2004;4:125-30. http://dx.doi.org/10.1016/j.meegid.2004. 02.001
21. Lora-Suárez F, Marín-Vásquez C, Loango N, Gallego $M$, Torres E, González MM, et al. Giardiasis in children living in post-earthquake camps from Armenia (Colombia). BMC Public Health. 2002;2:5. http://dx.doi.org/10.1186/14712458-2-5

22. Giraldo-Gómez JM, Lora F, Henao LH, Mejía S, GómezMarín JE. Prevalencia de giardiasis y parásitos intestinales en preescolares de hogares atendidos en un programa estatal en Armenia, Colombia. Rev Salud Pública. 2005;7:327-38. http://dx.doi.org/10.1590/S0124-00642005000300008

23. Trujillo de Vallejo F, Vargas-Bonilla N, Vallejo GA. Parasitismo intestinal y desnutrición en lactantes y preescolares de estrato social bajo en Ibagué-Tolima. Revista de la Asociación Colombiana de Ciencias Biológicas. 1991;5:64-75.

24. Thompson RC. Giardiasis as a re-emerging infectious disease and its zoonotic potential. Int J Parasitol. 2000;30: 1259-67. http://dx.doi.org/10.1016/S0020-7519(00) 00127-2

25. Santos CK, Grama DF, Limongi JE, Costa FC, Couto TR, Soares RM, et al. Epidemiological, parasitological and molecular aspects of Giardia duodenalis infection in children attending public daycare centers in Southeastern Brazil. Trans R Soc Trop Med Hyg. 2012;106:473-9. http:// dx.doi.org/10.1016/j.trstmh.2012.05.011

26. Volotão AC, Costa-Macedo LM, Haddad FS, Brandão A, Peralta JM, Fernandes O. Genotyping of Giardia duodenalis from human and animal samples from Brazil using beta-giardin gene: A phylogenetic analysis. Acta Trop. 2007;102:10-9. http://dx.doi.org/10.1016/j.actatropica.2007. 02.010

27. Rivero de RZ, Maldonado A, Bracho A, Castellanos M, Torres Y, Costa-León L, et al. Prevalencia de enteroparásitos, rotavirus y adenovirus en niños aparentemente sanos. Kasmera. 2009;37:62-73.

28. Scaramozzino P, Di Cave D, Berrilli F, D'Orazi C, Spaziani A, Mazzanti S, et al. A study of the prevalence and genotypes of Giardia duodenalis infecting kennelled dogs. Vet J. 2009;182:231-4. http://dx.doi.org/10.1016/j. tvjl.2008.07.003

29. Claerebout E, Casaert S, Dalemans AC, De Wilde N, Levecke V, Vercruysse J. et al. Giardia and other intestinal parasites in different dog populations in Northern Belgium. Vet Parasitol. 2009;161:41-6. http://dx.doi.org/10.1016/j. vetpar.2008.11.024

30. Abril A, Penagos JA. Determinación de parásitos gastrointestinales potencialmente zoonóticos en caninos de cinco municipios del departamento del Huila y riesgos para la salud pública (tesis). Bogotá: Universidad de la Salle; 2004.

31. Araujo W, Chávez A, Casas E, Falcón N. Prevalencia de Giardia sp. en Canis familiaris de los distritos de la provincia constitucional del Callao. Rev Inv Vet Perú. 2004;15:145-50.

32. Minvielle MC, Molina NB, Polverino D, Basualdo JA. First genotyping of Giardia lamblia from human and animal feces in Argentina, South America. Mem Inst Oswaldo Cruz. 2008;103:98-103. http://dx.doi.org/10.1590/S007402762008000100015

33. Pelayo I, Núñez FA, Rojas L, Furuseth E, Gjerde B, Wilke $\mathbf{H}$, et al. Giardia infections in Cuban children: The 
genotypes circulating in a rural population. Ann Trop Med Parasitol. 2008;102:585-95. http://dx.doi.org/10.1179/ $136485908 \times 355247$

34. Torres G, Zapata M, Restrepo M, Ríos L. Investigación científica sobre genotipificación y distribución de Giardia intestinalis en humanos y caninos de América. Salud Uninorte. 2011;27:49-62.

35. Ravid Z, Duque S, Arévalo A, Nicholls RS, Wasserman M. Genetic diversity of Giardia intestinalis populations in Colombia. Biomédica. 2007;27:37-41.

36. Read C, Walters J, Robertson ID, Thompson RC. Correlation between genotype of Giardia duodenalis and diarrhoea. Inter J Parasitol. 2002;32:229-31. http://dx.doi. org/10.1016/S0020-7519(01)00340-X

37. Kohli A, Bushen OY, Pinkerton RC, Houpt E, Newman RD, Sears CL, et al. Giardia duodenalis assemblage, clinical presentation and markers of intestinal inflammation in Brazilian children. Trans R Soc Trop Med Hyg. 2008;102:71825. http://dx.doi.org/10.1016/j.trstmh.2008.03.002

38. Feng Y, Xiao L. Zoonotic potential and molecular epidemiology of Giardia species and giardiasis. Clin Microbiol Rev. 2011;24:110-40. http://dx.doi.org/10.1128/ CMR.00033-10 